\title{
Outcome of papillary thyroid microcarcinoma: Study of 1,990 cases
}

\author{
ZHONG-ZHI LU ${ }^{1}$, YAN ZHANG ${ }^{2}$, SONG-FENG WEI ${ }^{2}$, DONG-SHENG LI ${ }^{1}$, \\ QING-HUA ZHU ${ }^{1}$, SI-JING SUN ${ }^{1}$, MIN LI $^{1}$ and LI LI ${ }^{1}$ \\ ${ }^{1}$ Department of General Surgery, The First Hospital of Zibo City, Zibo, Shandong 255200; \\ ${ }^{2}$ Department of Head and Neck Oncology, Tianjin Medical University, Tianjin 300070, P.R. China
}

Received November 13, 2014; Accepted December 29, 2014

DOI: $10.3892 / \mathrm{mco} .2015 .495$

\begin{abstract}
The present study examines the requirement of prophylactic neck node dissection in papillary thyroid microcarcinoma (PTMC) patients by analyzing high-risk factors of neck lymph node metastasis in PTMC. The clinical pathological data was a review of 1,990 patients diagnosed between January 2013 and January 2014. The data included information on patient gender, age, tumor size, multifocal, tumor pathological staging, bilateral thyroid cancer, the subtypes, $B R A F^{\mathrm{V} 600 \mathrm{E}}$ mutation, human telomerase reverse transcriptase ( $h T E R T)$, extrathyroidal invasion and neck lymph node metastasis. The univariate analysis $\left(\chi^{2}\right.$ test) showed that a number of factors were significantly associated with neck lymph node metastasis in PTMC $(\mathrm{P}<0.05)$ : Male gender, aged $<45$ years, extrathyroidal invasion, bilateral thyroid cancer, various subtypes (package type, follicular variant, diffuse sclerosing variant, eosinophils, tall cell and column variant), $B R A F^{\mathrm{v} 600 \mathrm{E}}$ mutation-positive, hTERT mutation-positive, pt3/4 and multifocality. The multivariate analysis (regression binary logistic) showed that the male gender, $<45$ years, tumor size $>5 \mathrm{~mm}$, extrathyroidal invasion, bilateral thyroid tumors, multifocality, $B R A F^{\mathrm{V} 600 \mathrm{E}}$ mutation-positive, $h T E R T$ mutation-positive and $\mathrm{pt} 3 / 4$ are associated with the neck lymph node metastasis in PTMC $(\mathrm{P}<0.05)$. These paired analysis results show that the subtypes of PTMC with tumor size $>5 \mathrm{~mm}$ is more common than the specific types of PTMC in which the tumor is $\leq 5 \mathrm{~mm}$ in neck lymph node metastasis. The neck lymph node metastasis incidence of the $>45$ years age group patients without high-risk factors in PTMC is 8.13 and $6.80 \%$, respectively. In conclusion, PTMC patients with high-risk factors only are recommended to undergo a prophylactic lymph node dissection.
\end{abstract}

Correspondence to: Dr Zhong-Zhi Lu, Department of General Surgery, The First Hospital of Zibo City, 4 East Emei mountain Road, Shandong 255200, P.R. China

E-mail: luzhongzhi73@126.com

Key words: papillary thyroid microcarcinoma, neck lymph node metastasis, neck lymph node dissection, risk factors

\section{Introduction}

With increasing numbers of patients, thyroid carcinoma has recently become the most common malignancy, ranking as the second to sixth malignancy in female cancers. Papillary thyroid microcarcinoma (PTMC) is defined as a papillary thyroid carcinoma (PTC) with the greatest dimensions $\leq 1.0 \mathrm{~cm}$, according to the World Health Organization classification system for thyroid tumors (1), and is often discovered incidentally during screening. However, PTMC has recently become the most common pathological subtype in PTC with the ultrasonography-guided fine-needle aspiration biopsy (FNAB) that facilitates the detection of PTMC in particular, and therefore, the incidence continues to rise. Since the prognosis of PTMC is good and is one of the few cancers that can be cured by surgery, which is often followed by radioiodine treatment, surgical treatment for PTMC requires certain standard guidelines to reduce recurrence and metastasis (2-8). The present study reviewed the clinical and pathological data of 1,990 patients that underwent PTMC surgery and analyzed the high-risk factors of neck lymph node metastasis in PTMC to determine the clinical necessity for neck lymph node dissection.

\section{Materials and methods}

Study population. The clinical data was reviewed on 1,990 PTMC patients between January 2013 and January 2014 in the Department of Head and Neck Oncology of Tianjin Medical University (Tianjin, China). The data included patients that underwent a side thyroidectomy and a central neck dissection or ipsilateral neck dissection on the same side, when lateral lymph node metastasis was confirmed by fine-needle aspiration cytology (FNAC). This was in accordance with the Chinese management guidelines for patients with thyroid nodules and differentiated thyroid cancer (8). The pathology of all the patients was identified as PTMC, as indicated by FNAC-guided by high-resolution ultrasonography and the aspiration pathology was confirmed by the surgical pathology. Two infant PTMC patients were excluded as thyroid cancer in children has different biological characteristics compared to adults. In addition, four patients of lymphoma with PTMC were excluded. The age range of patients with PTMC was 
13-74 years (median, 45 years) and the male to female ratio was 1:3.85. Among them, 1,339 were pN0, whilst 645 were $\mathrm{pN} 1$. The average number of lymph node metastases for lymph node positive patients was 3-16 (median, 4.8). The clinical and pathological data are listed in Table I.

Statistical analysis. Fisher's exact test or $\chi^{2}$ test was used to analyze the differences between the categorical data, whereas binary logistic regression was used to investigate the multifactor data, in which $\mathrm{P}<0.05$ was considered to indicate a statistically significant difference. SPSS software (version 17.0; SPSS, Inc., Chicago, IL, USA) was used for the data analysis.

\section{Results}

Univariate analysis outcome of the high-risk factors of neck lymph metastasis in PTMC. Univariate analysis showed that males, $<45$ years, extrathyroidal invasion, bilateral thyroid cancer, subtypes (package type, follicular variant, diffuse sclerosing variant, eosinophils, tall cell and column variant), $B R A F^{\mathrm{V} 600 \mathrm{E}}$ mutation-positive, human telomerase reverse transcriptase ( $h T E R T)$ mutation-positive, pt3/4 and multifocality were all significantly associated with the neck lymph node metastasis in PTMC $(\mathrm{P}<0.05)$. However, the difference between tumor sizes of $\leq 5$ and $>5 \mathrm{~mm}(211 / 630$ vs. 179/546, respectively) did not reach statistical significance $(\mathrm{P}=0.782)$ (Table I), which means that tumor size is not associated with neck lymph node metastasis in PTMC.

Multivariate analysis outcome of the neck lymph metastasis risk factors in PTMC. Multivariate analysis (binary logistic regression) showed that males, $<45$ years, tumor size $>5 \mathrm{~mm}$, extrathyroidal extension, bilateral thyroid tumors, multifocaltity, $B R A F^{\mathrm{V} 600 \mathrm{E}}$ mutation-positive, $h T E R T$ mutation-positive and $\mathrm{pt} 3 / 4$ were all significantly associated with the neck lymph node metastasis in PTMC $(\mathrm{P}<0.05)$. By contrast, the difference between the subtypes and non-subtypes in PTMC did not reach statistical significance $(\mathrm{P}=0.118)$ (Table II), which means that this factor is also not associated with the neck lymph node metastasis in PTMC.

Paired analysis outcome of tumor size and the subtypes in $P T M C$. The paired analysis showed that the tumor size is associated with the neck lymph node metastasis $(\mathrm{P}<0.05)$. Subtypes of PTMC with tumor size $>5 \mathrm{~mm}$ have a greater tendency of neck lymph node metastasis (Table III).

Outcome of neck lymph metastasis incidence without the high-risk factors. Hierarchical age group data shows that in patients without univariate analysis risk factors (such as males, extrathyroidal invasion, bilateral thyroid tumors, subtypes of tumor, multifocal, $B R A F^{\mathrm{V} 600 \mathrm{E}}$ mutation-positive and $\mathrm{pt} 3 / 4$ ) and those aged $\geq 45$ years in lymph node metastasis incidence is $8.13 \%$, which is statistically significant compared to those aged $<45$ years $(\mathrm{P}<0.05)$. The neck lymph metastasis incidence without multivariate analysis risk factors (such as males, bilateral thyroid cancer, tumor size $>5 \mathrm{~mm}$, multifocal, extrathyroidal invasion, $B R A F^{\mathrm{V} 600 \mathrm{E}}$ mutation-positive and pt3/4) in those aged $\geq 45$ years is $6.80 \%$, which was
Table I. Univariate analysis of PTMC neck lymph metastasis.

\begin{tabular}{|c|c|c|c|}
\hline Risk factor & $\begin{array}{l}\text { Lymph } \\
\text { node } \\
\text { cases, n }\end{array}$ & $\begin{array}{c}\text { Total } \\
\text { metastasis, } \\
\mathrm{n}(\%)\end{array}$ & P-value \\
\hline \multicolumn{4}{|l|}{ Age, years } \\
\hline $20-30$ & 128 & $74(57.81)$ & \multirow[t]{3}{*}{$<0.001$} \\
\hline $30-44$ & 761 & $272(35.74)$ & \\
\hline$\geq 45$ & 1,095 & $299(27.31)$ & \\
\hline \multicolumn{4}{|l|}{ Gender } \\
\hline Male & 409 & $202(49.39)$ & \multirow[t]{2}{*}{$<0.001$} \\
\hline Female & 1,575 & $443(28.13)$ & \\
\hline \multicolumn{4}{|c|}{ Tumor size, mm } \\
\hline$\leq 5$ & 630 & $211(33.49)$ & \multirow[t]{2}{*}{0.782} \\
\hline$>5$ & 1,354 & $179(32.78)$ & \\
\hline \multicolumn{4}{|c|}{ Extrathyroidal invasion } \\
\hline No & 631 & $106(16.80)$ & \multirow[t]{2}{*}{0.510} \\
\hline Yes & 1,353 & $539(39.84)$ & \\
\hline \multicolumn{4}{|c|}{ Single or double side tumor } \\
\hline Single side & 1,513 & $416(27.50)$ & \multirow[t]{2}{*}{$<0.001$} \\
\hline Double side & 471 & $229(48.62)$ & \\
\hline \multicolumn{4}{|l|}{ Subtypes } \\
\hline No & 1,895 & $607(32.03)$ & \multirow[t]{2}{*}{0.020} \\
\hline Yes & 89 & $39(43.82)$ & \\
\hline \multicolumn{4}{|c|}{ Tumor pathological staging } \\
\hline $\mathrm{pt} 3 / 4$ & 1,363 & $529(38.81)$ & $<0.001$ \\
\hline \multicolumn{4}{|c|}{$B R A F^{\mathrm{V} 600 \mathrm{E}}$ mutation } \\
\hline+ & 1,244 & $687(55.23)$ & \multirow[t]{2}{*}{0.023} \\
\hline- & 740 & $369(49.86)$ & \\
\hline \multicolumn{4}{|l|}{ hTERT } \\
\hline+ & 794 & $529(66.63)$ & \multirow[t]{2}{*}{$<0.001$} \\
\hline- & 1,190 & $577(48.49)$ & \\
\hline \multicolumn{4}{|c|}{ Number of primary lesion } \\
\hline Single & 1,182 & $284(24.03)$ & \multirow[t]{2}{*}{$<0.001$} \\
\hline Multifocality & 802 & $361(45.01)$ & \\
\hline
\end{tabular}

PTMC, papillary thyroid microcarcinoma; $h T E R T$, human telomerase reverse transcriptase.

statistically significant compared to those aged $<45$ years $(\mathrm{P}<0.05)$ (Table IV).

\section{Discussion}

The incidence of thyroid carcinoma is $6.2 \%$ per year and has increased in recent years (9). With the use of FNAB, which facilitates the detection of PTMC, the incidence is continuing to increase. Despite favorable biological features and good overall prognosis of thyroid carcinoma, there remain large differences in the surgical treatments for PTMC globally, which is particularly true in association with performing preventive prophylactic neck lymph dissection and is the focus of much controversy at present. With the progress of 
Table II. Multivariable analysis of PTMC neck lymph metastasis.

\begin{tabular}{|c|c|c|c|c|c|c|}
\hline Risk factor & $\begin{array}{l}\text { Partial regression } \\
\text { coefficient B }\end{array}$ & SE & Wald & DOF & P-value & $\operatorname{Exp}(B)$ \\
\hline Extrathyroidal invasion & -1.242 & 0.283 & 17.211 & 1 & $<0.001$ & 0.276 \\
\hline Subtypes & -0.368 & 0.226 & 2.540 & 1 & 0.109 & 0.684 \\
\hline Bilateral thyroid & -0.325 & 0.135 & 5.014 & 1 & 0.025 & 0.712 \\
\hline Tumor size & -0.362 & 0.146 & 6.133 & 1 & 0.013 & 0.697 \\
\hline Gender & -1.014 & 0.122 & 68.754 & 1 & $<0.001$ & 2.757 \\
\hline Age & 0.570 & 0.104 & 30.162 & 1 & $<0.001$ & 1.764 \\
\hline$B R A F^{\mathrm{V} 600 \mathrm{E}}$ mutation-positive & -0.395 & 0.189 & 9.276 & 1 & 0.037 & 0.771 \\
\hline hTERT mutation-positive & -0.847 & 0.136 & 35.864 & 1 & $<0.001$ & 1.897 \\
\hline T pathological staging & -0.382 & 0.172 & 8.463 & 1 & 0.027 & 0.747 \\
\hline Multifocality & -0.832 & 0.153 & 29.457 & 1 & 0.001 & 0.435 \\
\hline
\end{tabular}

PTMC, papillary thyroid microcarcinoma; SE, standard error; DOF, degrees of freedom; $h T E R T$, human telomerase reverse transcriptase.

Table III. Analysis of PTMC subtypes and differences in tumor size with lymph metastasis in PTMC.

\begin{tabular}{lrrrrrrrr}
\hline & \multicolumn{2}{c}{ Subtypes } & & \multicolumn{2}{l}{ Non-subtypes } & & \\
\cline { 2 - 3 } Item, mm & Yes & No & & Yes & No & P-value & OR \\
\hline$\leq 5$ & 2 & 11 & 118 & 498 & 0.031 & 0.202 \\
$>5$ & 36 & 40 & & 489 & 790 & $<0.001$ & 0.383 \\
\hline
\end{tabular}

PTMC, papillary thyroid microcarcinoma; OR, odds ratio.

the surgical techniques and the application of advanced equipment, preventive prophylactic lymph node dissection decreases the damage to the parathyroid glands and the laryngeal recurrent nerve. However, excessive treatment increases the probability of temporary parathyroid laryngeal damage and laryngeal nerves injury (10). Simultaneously, whether excessive treatment can generate maximum benefits to patients remains unknown.

The present study found that the neck lymph metastasis is associated with the male gender, those aged $<45$ years, extrathyroidal invasion, bilateral thyroid cancer, multifocality, $B R A F^{\mathrm{V} 600 \mathrm{E}}$ mutation-positive, hTERT mutation-positive and pt3/4. For tumor size and the subtypes, univariate analysis showed that a tumor size $>5 \mathrm{~mm}$ is associated with PTMC lymph node metastasis, but not the subtypes. However, the multivariate analysis conclusion showed that the tumor size and subtypes are associated with PTMC lymph node metastasis. PTMC is defined by the tumor diameter length, which differs from the early cancer and also low-risk cancers. Although the PTMC carcinoma subtypes have the characteristics of lymph node metastasis, tumor size remains as another of the biologically invasion signs (11). Evaluating the PTMC subtype carcinoma by clinical TNM and risk stratification is extremely valuable. The study of the paired statistics showed that the subtypes and tumor size correlated with lymph node metastasis in PTMC, particularly the subtypes with primary
Table IV. Neck lymph metastasis incidence without high-risk factors in the hierarchical age groups.

\begin{tabular}{lcccc}
\hline & \multicolumn{2}{c}{ Age group (years), n (\%) } & \\
\cline { 2 - 4 } $\begin{array}{l}\text { Neck lymph node } \\
\text { metastasis incidence }\end{array}$ & $14-30$ & $31-44$ & $\geq 45$ & \multirow{2}{*}{ P-value } \\
\hline Without univariate & $8 / 20$ & $19 / 138$ & $17 / 209$ & $<0.05$ \\
analysis risk factor & $(40.00)$ & $(13.77)$ & $(8.13)$ & \\
Without multivariate & $2 / 11$ & $16 / 105$ & $10 / 147$ & $<0.05$ \\
analysis risk factor & $(18.18)$ & $(15.24)$ & $(6.80)$ & \\
& & & &
\end{tabular}

tumor sizes $>5 \mathrm{~mm}$ have a greater tendency of neck lymph nodes metastasis and invasion.

The BRAF mutation was only present in the PTC and anaplastic/undifferentiated thyroid carcinomas, but not in the follicular or medullary thyroid carcinomas. In addition, it was associated with invasion, advanced pathological stage, lymph node metastasis and distant metastasis of PTC. As the $B R A F$ mutation appears to play an important role in PTC tumorigenesis, it has been postulated that this mutation may have a prognostic value. The present study found that the $B R A F^{\mathrm{V} 600 \mathrm{E}}$ mutation-positive rate was $62.70 \%$ and was associated with the neck lymph metastasis in PTMC. Besides, hTERT is the most common mutation in the promoter of the gene in thyroid cancers, which is prevalent in aggressive types of thyroid cancer, such as anaplastic thyroid cancer and poorly differentiated thyroid cancer, as well as $B R A F^{\mathrm{V} 600 \mathrm{E}}$ mutation-positive PTC. The study found that the hTERT mutation-positive rate was $40.02 \%$, and it is also associated with the neck lymph metastasis in PTMC. Therefore, $B R A F$ and $h T E R T$ mutations may be useful molecular markers for assisting in the risk stratification for patients with PTMC. The results of the study are consistent with those in the studies by Xing et al $(12,13)$.

The male gender has been consistently recognized as an independent risk factor of lymph node metastasis in thyroid carcinoma (14). Females are comparatively prone to thyroid 
carcinoma due to their estrogen levels (ratio of males to females was 1:3.85 in the present study). However, the male incidence of thyroid carcinoma is associated with their living environment, in which certain protection mechanisms possibly exist. Once the protection mechanism is damaged, males will be exposed to malignant thyroid progression and lymph node metastasis. Therefore, once a male is diagnosed with PTMC, surgical intervention would possibly improve their prognosis.

Adolescents are more likely to develop neck lymph node metastasis (15). The present study shows that the incidence of neck lymph node metastasis for those who are $<30$ years old (except children) without univariate and multivariate risk factors was 18.18 and $40 \%$, respectively, whereas in those who are $>45$ years without the risk factors, the incidence was only 6.8 and $8.13 \%$, respectively; the incidences are statistically significant. Although it is commonly recognized that those aged $>45$ years are at risk of tumor recurrence and lymph node metastasis, those $>45$ years without risk factors and those without clinically palpable lymph nodes or ultrasound results that are suggestive of metastasis are not recommended to undergo prophylactic lymph dissection.

Extrathyroidal invasion (16), multifocality (17) and bilateral thyroid tumors of PTMC (18) are the important risk factors in lymph node metastasis that represent biological characteristics of progress. Although the study by McCarthy et al (19) reported that multifocality is highly homologous within the gland and is not associated with tumor invasion, Shindo et al (17) and Chow et al (20) found that neck lymph node metastasis and tumor multifocality remain significantly correlated, which is the major reason for lymph node metastasis. The present study is consistent with their findings.

The incidence of papillary thyroid carcinoma has been reported in the range of $0.5-5.2 \%$ and neck lymph node metastasis is $3.1-18.2 \%$ in autopsy specimens (21). By contrast, the prevalence of clinical thyroid papillary carcinoma was 1.9-11.7 per 100,000 people of all ages (22), suggesting that the subclinical thyroid carcinoma is almost one thousand times lower than the apparent clinical type. A previous study (23) even suggested that patients without high-risk factors of thyroid carcinoma should not immediately undergo surgery. Neck lymph node metastasis does not affect the PTMC prognosis (24), even with re-operation following recurrence. A previous study (25) reported that the recurrence during prophylactic neck lymph nodes dissection is higher compared to those not undergoing surgery. In addition, prophylactic neck lymph nodes dissection can increase the temporary postoperative parathyroid functional damage and the risk of injury to laryngeal nerves, which can affect the patient quality of life. The present study shows that the neck lymph node metastasis incidence without a high-risk factor in PTMC is only $6.80-8.13 \%$, so it is suggested that prophylactic neck lymph nodes dissection should not to be performed for PTMC patients without high-risk factors.

In conclusion, neck lymph node metastasis significantly correlated with males, aged $<45$ years, extrathyroidal invasion, multifocal, bilateral, $B R A F^{\mathrm{V} 600 \mathrm{E}}$ mutation-positive, $h T E R T$ mutation-positive and pt $3 / 4$, and tumor size $>5 \mathrm{~mm}$ with the subtypes in PTMC. PTMC patients without high-risk factors should be individually treated according to these strategically high-risk factors. PTMC patients without high-risk factors are not recommended to undergo prophylactic lymph node dissection to maximize functionality.

\section{Acknowledgements}

The authors would like to thank the team members of the Department of Head and Neck Oncology, Tianjin Medical University (Tianjin, China) for their participation.

\section{References}

1. Hedinger C, Williams ED and Sobin LH: The WHO histological classification of thyroid tumors: a commentary on the second edition. Cancer 63: 908-911, 1989.

2. Cooper DS, Doherty GM, Haugen BR, et al: Revised American Thyroid Association management guidelines for patients with thyroid nodules and differentiated thyroid cancer. Thyroid 19: 1167-1214, 2009.

3. Pfister DG, Spencer S, Brizel DM, et al: Head and neck cancers, Version 2.2014. Clinical practice guidelines in oncology. J Natl Compr Canc Netw 12: 1454-1487, 2014.

4. Pacini F, Castagna MG, Brilli L and Pentheroudakis G; ESMO Guidelines Working Group: Thyroid cancer: ESMO Clinical Practice Guidelines for diagnosis, treatment and follow-up. Ann Oncol Suppl 7: vii110-vii119, 2012.

5. Yoshida A: Guidelines for the management of thyroid tumors. Nihon Geka Gakkai Zasshi 113: 507-601, 2012 (In Japanese).

6. Takami H, Ito Y, Okamoto T, Onoda N, Noguchi H and Yoshida A: Revisiting the guidelines issued by the Japanese Society of thyroid surgeons and Japan association of endocrine surgeons: a gradual move towards consensus between Japanese and western practice in the management of thyroid carcinoma. World J Surg 38: 2002-2010, 2014.

7. The Japanese Society of Thyroid Surgery and The Japanese Association of Endocrine Surgeons: Guidelines for Management of Thyroid Tumor. Kanehara Press, Tokyo, pp, 2010.

8. Teng W, Liu YF, Gao M and Huang G: Management guidelines for patients with thyroid nodules and differentiated thyroid cancer. Chin J Clin Oncol 17: 1249-1272, 2012 (In Chinese).

9. Jemal A, Siegel R, Ward E, Hao Y, Xu J and Thun MJ: Cancer statistics, 2009. CA Cancer J Clin 59: 225-249, 2009.

10. Khairy GA and Al-Saif A: Incidental parathyroidectomy during thyroid resection: incidence, risk factors, and outcome. Ann Saudi Med 31: 274-278, 2011.

11. Burningham AR, Krishnan J, Davidson BJ, Ringel MD and Burman KD: Papillary and follicular variant of papillary carcinoma of the thyroid: initial presentation and response to therapy. Otolaryngol Head Neck Surg 132: 840-844, 2005.

12. Xing M, Westra WH, Tufano RP, et al: BRAF mutation predicts a poorer clinical prognosis for papillary thyroid cancer. J Clin Endocrinol Metab 90: 6373-6379, 2005.

13. Xing M, Liu R, Liu X, et al: BRAF V600E and TERT promoter mutations cooperatively identify the most aggressive papillary thyroid cancer with highest recurrence. J Clin Oncol 32: 2718-2726, 2014

14. Koo BS, Choi EC, Yoon YH, Kim DH, Kim EH and Lim YC: Predictive factors for ipsilateral or contralateral central lymph node metastasis in unilateral papillary thyroid carcinoma. Ann Surg 249: 840-844, 2009.

15. Handkiewicz-Junak D, Wloch J, Czarniecka A, et al: Completion total thyroidectomy in children with differentiated thyroid cancer. Endokrynol Pol 57: 356-361, 2006 (In Polish).

16. Chung YS, Kim JY, Bae JS, et al: Lateral lymph node metastasis in papillary thyroid carcinoma: results of therapeutic lymph node dissection. Thyroid 19: 241-246, 2009.

17. Shindo M, Wu JC, Park EE and Tanzella F: The importance of central compartment elective lymph node excision in the staging and treatment of papillary thyroid cancer. Arch Otolaryngol Head Neck Surg 132: 650-654, 2006.

18. Mercante G, Frasoldati A, Pedroni C, et al: Prognostic factors affecting neck lymph node recurrence and distant metastasis in papillary microcarcinoma of the thyroid: results of a study in 445 patients. Thyroid 19: 707-716, 2009.

19. McCarthy RP, Wang M, Jones TD, Strate RW and Cheng L: Molecular evidence for the same clonal origin of multifocal papillary thyroid carcinomas. Clin Cancer Res 12: 2414-2418, 2006. 
20. Chow SM,Law SC, Chan JK, Au SK, Yau S and Lau WH: Papillary microcarcinoma of the thyroid - prognostic significance of lymph node metastasis and multifocality. Cancer 98: 31-40, 2003

21. Harach HR, Franssila KO and Wasenius VM: Occult papillary carcinoma of the thyroid. A 'normal' finding in Finland. A systematic autopsy study. Cancer 56: 531-538, 1985.

22. Ito Y, Tomoda C, Uruno T, et al: Prognostic significance of extrathyroid extension of papillary thyroid carcinoma: massive but not minimal extension affects the relapse-free survival. World J Surg 30: 780-786, 2006
23. Ito $\mathrm{Y}$, Miyauchi $\mathrm{A}$, Inoue $\mathrm{H}$, et al: An observational trial for papillary thyroid microcarcinoma in Japanese patients. World J Surg 34: 28-35, 2010.

24. Ito Y, Jikuzono T, Higashiyama T, et al: Clinical significance of lymph node metastasis of thyroid papillary carcinoma located in one lobe. World J Surg 30: 1821-1828, 2006.

25. Noguchi S, Yamashita H, Murakami N, Nakayama I, Toda M and Kawamoto H: Small carcinomas of the thyroid. A long-term follow-up of 867 patients. Arch Surg 131: 187-191, 1996. 